\title{
A study to compare the use of fusidic acid viscous eye drops and choramphenicol eye ointment in an accident and emergency department
}

\author{
M. R. JAMES, R. BROGAN \& M. CAREW-MCCOLL \\ Department of Accident and Emergency, Royal Preston Hospital, Sharoe Green Lane, \\ Fulwood, Preston
}

\section{SUMMARY}

A total of 300 patients attending an Accident and Emergency department with ophthalmic complaints needing topical antibiotic treatment were treated with fucithalmic or chloramphenicol (chloromycetin). Their compliance and the incidence of side effects were assessed.

There was a $70.3 \%$ response rate to the questionnaire. Of the patients $51.3 \%$ using fucithalmic completed the 5 day course compared with $37 \cdot 2 \%$ of those taking chloramphenicol. However, no patients were found to have suffered as a result of failing to complete the course. The incidence of side effects was similar in both groups.

\section{INTRODUCTION}

Chloramphenicol eye ointment $1 \%$ (Chloromycetin) is used widely for treatment and prophylaxis against eye infections in Accident and Emergency departments. It is usually given q.d.s. as a 5 day course. Fusidic acid is now available in a sustained release preparation as viscous eye drops (Fucithalmic 1\%); it is administered b.d. and has been shown to have an adequate antimicrobial spectrum (Hansen, 1985, Van Bijsterveld et al., 1987). The hospital prescribing cost is approximately $50 \%$ more than Chloromycetin. The ease of administration of Fucithalmic and the b.d. dosage may increase patient compliance, especially in those conditions with short lived discomfort such as following removal of foreign bodies. The aim of the study was to assess patient compliance and side effects for both drugs in patients attending an A\&E department with a variety of eye conditions.

Correspondence: Mr. M. R. James, Senior Registrar in Accident and Emergency, Royal Preston Hospital, Sharoe Green Lane, Fulwood, Preston, PR2 4HT 


\section{METHOD}

A total of 300 patients attending the A\&E department at Royal Preston Hospital $\stackrel{\vec{Q}}{<}$ with eye complaints requiring antibiotic treatment or prophylaxis were included $\stackrel{\circ}{\circ}$ in the study e.g. foreign bodies, bacterial conjunctivitis, corneal abrasions and arc eye. The categories of patients excluded from the study are listed in Table 1.

Treatment was randomly allocated on the basis of their A\&E registration number. Those with even numbers were given chloramphenicol and those with odd numbers fucithalmic. The small group of patients who had complaints affecting both eyes were asked to use chloramphenicol in the right eye and fucithalmic in the left eye. Each patient was shown how to use the ointment and told to apply it for 5 days the chloramphenicol q.d.s. and the fucithalmic b.d.

All patients were told that they would be sent a questionnaire following treatment; $\vec{\omega}$ they were not told that their compliance would be monitored. The questionnaires $\mathbb{Q}$ were sent out 4 days after their initial visit. The questionnaires asked how many $\stackrel{3}{\circ}$. days they had used the treatment for and, if they had failed to complete the 5 day iv course, the reasons for this. They were also asked what side effects they had $\vec{N}$

experienced if any. returned with problems from the treatment.

\section{RESULTS}

Of the 300 patients, 160 received fucithalmic, 124 chloramphenicol, and 16 had bilateral complaints. The incidence of different conditions was similar in both treatment groups. A total of $211(70.3 \%)$ of the patients replied to the questionnaire. The reply rate was similar in the groups receiving each treatment; $71.8 \%$ for those who had fucithalmic and $69.3 \%$ for those who had chloramphenicol. In the group of patients who had corneal abrasions there was a $91 \%$ response rate.

The percentage of patients completing the course was $51.3 \%$ for those taking fucithalmic and $37.2 \%$ for those taking chloramphenicol $\left(P<0.05\right.$ using $X^{2}$ with Yates correction) see Table 2.

The reasons given for failing to complete the course were similar in both treatment groups, as was the incidence of the various side effects (see Tables 3 \& 4.)

There were 8 patients with bilateral complaints who answered the questionnaire, $\rightarrow$

Table 1 To show the categories of patient excluded from the study.

(1) Allergy to either drug

(2) Use of either drug in the last 10 days

(3) Under 16 years old

(4) Previous eye pathology e.g. glaucoma, surgery. 
Table 2 To show the percentage of patients completing the course of treatment for the different diagnostic categories. (Actual numbers in brackets.)

\begin{tabular}{|c|c|c|c|c|}
\hline & \multicolumn{4}{|c|}{ Complaint } \\
\hline & FB & Conjunctivitis & Abrasion & Others \\
\hline $\begin{array}{l}\% \text { completing course } \\
\text { or more - Chl. } \\
(32 / 86)\end{array}$ & $\begin{array}{c}39 \% \\
(19 / 49)\end{array}$ & $\begin{array}{l}42 \% \\
(5 / 12)\end{array}$ & $\begin{array}{r}35 \% \\
(8 / 23)\end{array}$ & $(0 / 2)$ \\
\hline $\begin{array}{l}\% \text { completing course } \\
\text { or more - Fuc. } \\
(59 / 115)\end{array}$ & $\begin{array}{c}47 \% \\
(34 / 73)\end{array}$ & $\begin{array}{l}69 \% \\
(9 / 13)\end{array}$ & $\begin{array}{c}54 \% \\
(15 / 28)\end{array}$ & $(1 / 1)$ \\
\hline
\end{tabular}

Table 3 Showing the reasons given by patients for failing to complete the 5 day course. Some patients gave more than one reason. (Actual numbers in brackets.)

\begin{tabular}{lcc}
\hline & \multicolumn{2}{c}{ Treatment given } \\
Reason & Fucithalmic (56) & Chloramphenicol (54) \\
\hline Condition better & $82 \%(46 / 56)$ & $87 \%(47 / 54)$ \\
Awkward to apply & $13 \%(7 / 56)$ & $15 \%(8 / 54)$ \\
Side effect & $29 \%(16 / 56)$ & $32 \%(17 / 54)$ \\
\hline
\end{tabular}

Table 4 To show the incidence of side effects experienced by patients.

\begin{tabular}{lcc}
\hline & \multicolumn{2}{c}{ Treatment Group } \\
Side effect & Chloramphenicol & Fucithalmic \\
\hline Itching & $4 \%$ & $2 \%$ \\
Stinging & $11 \%$ & $18 \%$ \\
Discomfort & $7 \%$ & $4 \%$ \\
Blurring & $20 \%$ & $13 \%$ \\
Other & $4 \%$ & $5 \%$ \\
\hline
\end{tabular}

of these 5 stated that they preferred fucithalmic (not significant). Their results were not included with those patients having unilateral complaints.

When the notes were reviewed at 1 month, 6 sets of notes were untraceable. Of the 294 found there were 3 medication changes, 2 patients with conjunctivitis had not responded to chloramphenicol and had been changed to fucithalmic, and one case where chloramphenicol had caused irritation and the patient had been changed to fucithalmic.

\section{DISCUSSION}

The results of this study demonstrate that there was a significantly higher percentage 
of patients completing the fucithalmic courses than the chloramphenicol. However, no patients from either group returned with problems attributable to failure to complete the recommended course of treatment.

The incidence of side effects with both drugs was very similar, with fucithalmic causing more stinging and chloramphenicol more blurring. This correlates with other studies (Sinclair \& Leigh, 1988).

Fucithalmic appears to offer some advantages over chloramphenicol. It is given as a twice daily dosage, is easier to apply and causes less blurring of vision which is more acceptable to patients, especially those who are still working. No serious side effects have been reported from fucithalmic but there have been several reports of aplastic anaemia following ophthalmic use of chloramphenicol (Dutro, 1981; Fraunfelder et al., 1982; Stevens \& Mission, 1987; Baruhart, 1988) ophthalmic use of chloramphenicol. This reaction appears not to be dose related, occurs weeks to months after treatment and is very rare as only a few cases have been reported in the world literature yet chloramphenicol is in widespread use in ophthalmic preparations. There is some controversy in the literature as to whether these cases of aplastic anaemia are due to chloramphenicol (Flach, 1982).

The main disadvantages of fucithalmic are its higher cost and its possible efficacy with a 12 hourly dosage interval. However, we had no clinical treatment failures in this study. Pharmacokinetic studies have shown the concentration in the tears to be greater than the minimum inhibitory concentration (MIC) at 12 hours to most, but not all, common pathogens and a further (Van Bijsterveld et al., 1987) study also showed that the concentration achieved in the aqueous humor is comparable with that achieved with systemic administration of fucidit (Hansen, 1985).

These results show no outstanding benefit for fucithalmic over chloramphenicol: In view of the higher cost of fucithalmic we are not changing from our current use of chloramphenicol as antibiotic of first choice for ophthalmic treatment.

\section{ACKNOWLEDGEMENT}

We would like to thank Leo Laboratories Limited for funding the postage for the questionnaires.

\section{REFERENCES}

Baruhart E. (1988) (ed.) Physicians Desk Reference. 42nd Edition. 1529-30.

Dutro M. P. (1981) Chloramphenicol and aplastic anaemia. American Journal of Ophthalmology 92 (6), 870.

Flach A. J. (1982) Chloramphenicol and aplastic anaemia (letter). American Journal of Ophthalmology 93 (5), 664-666.

Fraunfelder F. T., Bagby G. C. \& Kelly D. J. (1982) Fatal aplastic anaemia following topical administration of ophthalmic chloramphenicol. American Journal of Ophthalmology 93 (3), 356-360. 
Hansen S. (1985) Intraocular penetration of fusidic acid with topical fucithalmic. European Journal of Drug Metabolism and Pharmacokinetics, 10 (4), 329-331.

Hvidberg J. (1987) Fusidic acid in acute conjunctivitis. Acta Ophthalmologica, 65 (1), 43-47.

Sinclair N. M. \& Leigh D. A. (1988) A comparison of fusidic acid viscous eye drops and chloramphenicol eye ointment in acute conjunctivitis. Current Therapeutic Research 44 (3), 468-474.

Stevens J. D. \& Mission G. P. (1987) Ophthalmic use of chloramphenicol. Lancet, Dec. 19, 1456.

Van Bijsterveld O. P., Andriesse H. \& Nielsen B. H. (1987) Fusidic Acid in Tear Fluid:- Pharmacokinetic study with fusidic acid viscous eye drops.

European Journal of Drug Metabolism and Pharmacokinetics, 12 (3), 215-218. 